\title{
Designing an Optimal Crisis Management Model with the Approach of Human Resource Management System in the Iranian Red Crescent Society
}

\author{
Bahram Gheibi $^{1} \oplus$, Karamollah Danesh Fard ${ }^{2} \oplus$, Parvaneh Golard $^{3} \oplus$
}

Date of submission: 01 Oct. 2020 Date of acceptance: 02 Nov. 2020

\section{Original Article}

\begin{abstract}
INTRODUCTION: In times of crisis and disasters, the Red Crescent Society is faced with wide and diverse duties and quality of human resources (HRs) in management departments and high organizational levels. One of the most important reasons for the success of HR projects in crises is the sufficient attention paid to the job requirements and the feasibility of implementing each of the crisis management strategies at different levels of the organization. Therefore, this study was conducted to present the current state of HR architecture of the organization based on the HR management system considering the HR architecture model in 2020.
\end{abstract}

METHODS: In this study, the Delphi method was used to collect the necessary data. The statistical population of this study $(\mathrm{n}=15)$ consisted of academic and organizational experts who had expertise in crisis management and HR management. The samples were selected using purposive and snowball sampling techniques. To conduct the research, a 30-item questionnaire (each item representing a variable) was designed with applying weight restrictions in the model and distributed among the subjects. The reliability of each variable was confirmed using Cronbach's alpha coefficient method ( $\alpha>0.7)$.

FINDINGS: Based on the findings, in the optimal HR management system, the most attention should be paid to recruiting HRs to have the highest performance speed in crisis management. Moreover, to have the least uncertainty in crisis management, HR improvement needs the most attention. It was also found out that the least amount of organizational disorder in crisis management would be experienced by devoting great attention to the maintenance of HR. Finally, to have the most response options in crisis management, recruitment of HR should be taken into consideration mostly

CONCLUSION: The greatest attention should be paid to recruiting HRs in the optimal HR management system to have the largest number of response options in crisis management. This means that, according to the conceptual model, the emphasis on employing analyst staff would maximize the number of response options in times of crisis incidence. Therefore, to succeed in this field, the organization must reconsider its recruitment policies in a way that leads to the entry of capable employees with the ability to solve problems in the organization. The ability to suggest and review different solutions in problem-solving and make the best decision are largely an inherent characteristic of individuals. The recruitment of capable people in this field would increase the options for dealing with the crisis and improve the efficiency of the decisions and actions. The second and last priorities in this area were respectively related to maintenance and improvement.

Keywords: Crisis Management; Human Resource Management; Delphi Technique; Red Crescent.

How to cite this article: Gheibi B, Danesh Fard K, Golard P. Designing an Optimal Crisis Management Model with the Approach of Human Resource Management System in the Iranian Red Crescent Society. Sci J Rescue Relief 2020; 12(4): 279-87.

\footnotetext{
1. Department of Public Management-Human Resources, Qeshm Branch, Islamic Azad University, Qeshm, Iran

2. Professor of governmental Management Science and Research Branch, Islamic Azad University, Tehran, Iran

3. Associate Professor, Department of Public Management, South Tehran Branch, Islamic Azad University, Tehran, Iran

Correspondence to: Karamollah Danesh Fard, Email: Daneshfard@srbiau.ac.ir
} 


\section{Introduction}

$\mathrm{T}$ oday, societies are dealing with unpredictable and changing environments and are constantly confronting environmental challenges. Organizations, regardless of their type and size, are faced with various internal and external influential factors making the time of achieving their goals uncertain. The effect of this uncertainty on the goals of the organization is called crisis (1). Crisis is a concept specifically referring to general examples such as disintegration, disorder, mental transformation, excessive fragility, value threat, socio-political instability, and military conflict. Therefore, this concept refers to the unrest circumstances in the national and transnational contexts. In this respect, it is better to claim that there is no society and organization without a crisis (2).

The wisdom of crisis management dictates to managers that communities and organizations can reduce potential mistakes in crisis management by properly monitoring the environment and preparing programs to deal with crises and instantaneous events (3). Among the effective tools in crisis incidence are human resources (HRs) that can significantly reduce the amount of potential damage provided that they are being properly managed. The reason for the importance of human resources lies in the fact that the occurrence of natural disasters and lack of proper human resource planning to deal with the damage and the resulting message, can lead to the loss of resources. The compensation and repair of resources can last long due to environmental changes and unpredictable factors.

The traditional role of HRs has evolved significantly and changed to taking other workplace-based responsibilities. In other words, the role of HRs has transformed from hiring and firing to more complex roles that directly affect organizational performance (4). Regarding this, the role of HRs has expanded and requires new and abundant knowledge and skills to ensure that organizational needs are satisfied. Crisis management is among the areas of management in which HRs are expected to participate with the view of ensuring that the needs of staff during and after the crisis are taken into account during the development of crisis management plans (5).

The prevalence of crises and accidents in organizations has considerably increased recently, resulting in the appearance of various kinds of threats in an organization (6). Therefore, it is necessary to raise the staff's awareness of such threats and include supportive and relief measures to address crises. Accordingly, crisis management can prioritize the important role of HRs. Among the main tasks of governments are effective policy-making, providing the necessary facilities and resources, formulating appropriate forecasts, preparing proper scenarios, and implementing planned actions before, during, and after the crisis incidence. However, these measures are performed differently from country to country. One of the most important organizations that has worked in the field of human dignity, alleviation of human suffering, and promotion of peace and friendship is the Iranian Red Crescent Society, which their important role in crisis management is admitted by everyone (7).

Humanitarian organizations, including the International Committee of the Red Cross and Red Crescent, and their members, such as the Iranian Red Crescent Society, face numerous challenges and issues in achieving their goals of providing effective assistance to vulnerable and affected individuals and promoting peace and friendship, understanding, and humanitarian values. Moreover, one of the most prominent challenges of such organizations in the field of human resource management is the creation of necessary mechanisms to anticipate and provide human, financial, and logistical resources and capacities for the efficient execution of organizational tasks and missions.

The Red Crescent Society faces wide and diverse tasks and quality of HRs in management departments and high organizational levels, as well as the lack of proper development of structure and organization, align with the new established goals and missions. The evidence of this problem can be the lack of proportion between the staff's job description and the actual issues the organization deals with. Moreover, in some cases, the staff of the Red Crescent Society has capabilities that are not realized by performing the duties defined in the organizational job descriptions. The staff of Red Crescent has a large number of responsibilities which are also particularly important due to their direct connection with the employee's security. Therefore, these staffs spend a lot of their time in the workplace and when they are at home, they are still in connection with work and must be ready to attend to the workplace (7). 
It seems that discovering the relationship between the two concepts of crisis management and HR management can facilitate the improvement of services provided by the Red Crescent on the one hand and create a safe, resilient, and prepared community. Limited measures have already been employed to develop a crisis management model. One of the most important reasons for the success of such models is paying sufficient attention to the job requirements and assessing the feasibility of implementing each of the crisis management strategies at different levels of the organization. Therefore, this study was conducted to present the current state of HR architecture of the organization based on the HR management system considering the HR architecture model in 2020.

\section{Methods}

In this study, the Delphi method was used to collect the necessary data. The statistical population of this study consisted of academic and organizational experts who had expertise in crisis management and HR management. The samples were selected using purposive and snowball sampling techniques. The researcher requested his research supervisor and advisor to introduce other experts who had $\mathrm{PhD}$ degrees and 28 years or more experience in crisis and HR management.

The initial participants were asked to refer their peers to the researcher, and the researcher accessed a network of interpersonal and organizational information of a group of experts and found the potential effective subjects using this network. Referrals to the experts continued until the selected individuals were convergence based on the experts' opinions. Regarding this, convergence was achieved by selecting 15 subjects.

It was necessary to identify themes and subthemes to design the model. In order to identify the influencing factors, the indicators were extracted from different articles and during various meetings held with experts. Due to a large number of identified variables, weight restrictions were applied in the model to reduce the inputs and determine the importance of the inputs relative to each other. To this end, a 30item questionnaire (each item representing a variable) was designed and was distributed among the 15 expert respondents, which were filled out comprehensively and completely. The questionnaires were qualitatively scaled and scored on a 7-point Likert scale (from very low to very high).

After collecting the questionnaires, the Fuzzy Delphi method was applied to determine the most important factors. In this respect, three steps of expert surveys were conducted. In the first survey step, the presented conceptual model along with the sub-criteria was sent to the members of the expert group. The experts' extent of agreement with each criterion was acquired and their proposed and corrective points of view were applied. The obtained definite mean showed the extent of the experts' agreement with each research criterion.

In the second survey step, the second questionnaire was prepared and sent to the same members of the expert group, with the opinions of the previous expert and its extent of the disagreement with the others' points of view. In the second step, the members of the expert group answered the questions again according to the point of view of the other members of the group. In the third step of the survey, the necessary changes were made in the components of the model, and the third questionnaire was prepared and sent back to the experts along with the experts' previous points of view and their extent of difference with the mean point of other experts' opinions. The reliability of the instrument used in the research was determined using Cronbach's alpha coefficient method, which is presented in Table 1.

For each of the variables, Cronbach's alpha coefficient of higher than 0.7 was confirmed. In order to determine the validity of the questionnaire, the opinions of experts were obtained and its validity was confirmed. Moreover, since the interviews as the audit method were performed, after collecting and analyzing the data, the derived categories were shown to the experts to confirm the accuracy of the material and guarantee and obtain the expected reliability for research.

To formulate a conceptual model, the table of four crisis groups was used from Burnett's point of view (8). In this table, the four groups of crises were written in the vertical columns and the main HR management systems were written in horizontal columns and the data were collected based on the intersection of each axis, determining how to make this matrix in the crisis to derive the most efficiency. The criteria of threat 
Table 1. Components and items of the designed questionnaire to perform the Delphi technique Dimensions Components

Assessing the type of employees in the field of recruitment in increasing the performance speed

Assessing the type of employees in the field of recruitment in reducing organizational uncertainty

Assessing the type of employees in the field of recruitment in reducing organizational disorder

Assessing the type of employees in the field of recruitment in increasing the number of responsive options

Assessing the type of employees in the field of improvement in increasing the performance speed

Variables used in the field of human resource management system
Assessing the type of employees in the field of improvement in reducing organizational uncertainty

Assessing the role of employees in the field of improvement in reducing organizational disorder

Assessing the role of education and improvement in increasing the number of responsive options

Assessing the type of employees in the field of maintenance in increasing the performance speed

Assessing the type of employees in the field of reducing organizational uncertainty

Assessing the role of maintenance field in reducing organizational disorder

Assessing the role of maintenance field in increasing the number of response options level, time pressure, and event intensity, as well as the number of response or reaction options, constituted the matrix for crisis classification. The three systems of recruitment /selection, improvement, and training and appointment were considered as the main components of HR management. Subsequently, all the matrix boxes were checked.

\section{Findings}

In the initial survey step, the presented conceptual model along with the description of the criteria was sent to the members of the expert group. Afterward, the experts' agreement with each criterion was obtained and their proposed and corrected points of view were applied. This step was accomplished by including all criteria into the second step. In the second survey step, the second questionnaire was prepared and sent to the same members of the expert group, with the opinions of the previous expert and its extent of disagreement with the others' points of view. In the second step, the members of the expert group answered the questions again according to the point of view of the other members of the group (Table 2).
According to the views presented in the first step and its comparison with the results of the second step, if the difference between the two steps were less than the threshold of 0.2 , the survey process was terminated. Regarding some components, the members of the expert group have reached a consensus and the extent of disagreement in the first and second steps was less than the threshold of 0.2 . Therefore, the survey on the above components was stopped. On the other hand, among the mentioned components, the components in which the non-fuzzy mean of experts' opinions was obtained less than 9 , were removed from the conceptual model of the research. In this step, 23 components were stopped and the survey was continued on the remaining 7 components, which was performed in the third step.

In the third step of the survey, the necessary changes were made in the components of the model, and the third questionnaire was prepared and sent back to the experts along with the experts' previous points of view and their extent of difference with the mean point of other experts' opinions (Table 3 ).

Based on the results of Table 3, the disagreement extent of experts in the second and 
Table 2. Results of the second survey step and the mean of experts' opinions

\begin{tabular}{|c|c|c|c|c|c|c|c|c|c|c|c|c|c|c|}
\hline 究 & Numerical value & $\frac{3}{\frac{3}{0}}$ & $\begin{array}{l}\frac{3}{6} \\
\frac{3}{2} \\
\frac{0}{0} \\
\frac{\pi}{0}\end{array}$ & $\stackrel{5}{\tilde{c}}$ & $\frac{\hat{n}}{\hat{n}}$ & $\stackrel{\ominus}{\stackrel{E}{E}}$ & 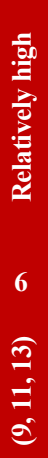 & $\begin{array}{l}7 \\
\overparen{n} \\
\stackrel{n}{E} \\
=\end{array}$ & 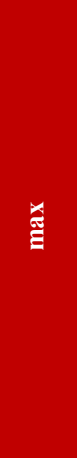 & $\bar{\Xi}$ & 豆 & 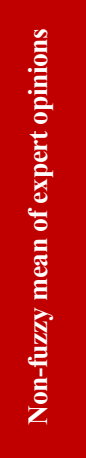 & 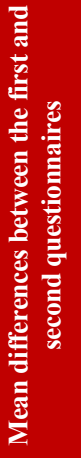 & $\frac{\mathscr{2}}{\bar{E}}$ \\
\hline 1 & $\begin{array}{l}\text { Creative and innovative } \\
\text { staff }\end{array}$ & 0 & 0 & 0 & 0 & 8 & 4 & 3 & 8.98 & 11.35 & 13.73 & 11.35 & 0.13 & accept \\
\hline 2 & Multi-skilled staff & 0 & 0 & 0 & 0 & 4 & 9 & 3 & 9.94 & 12.31 & 14.70 & 12.32 & 0.00 & accept \\
\hline 3 & Flexible staff & 0 & 0 & 1 & 1 & 6 & 2 & 5 & 8.50 & 10.95 & 13.38 & 10.94 & 0.13 & accept \\
\hline 4 & Analyst staff & 0 & 0 & 0 & 0 & 3 & 11 & 1 & 9.19 & 11.59 & 13.99 & 11.59 & 0.45 & Next \\
\hline 5 & Informal learning & 0 & 0 & 0 & 2 & 7 & 3 & 3 & 8.41 & 10.80 & 13.20 & 10.80 & 0.13 & accept \\
\hline 6 & $\begin{array}{l}\text { Coaching and } \\
\text { mentoring }\end{array}$ & 0 & 0 & 1 & 0 & 7 & 4 & 3 & 8.70 & 11.15 & 13.57 & 11.14 & 0.13 & accept \\
\hline 7 & $\begin{array}{l}\text { Continuous training to } \\
\text { maintain morale and } \\
\text { composure }\end{array}$ & 0 & 1 & 0 & 1 & 3 & 7 & 3 & 8.29 & 11.02 & 13.54 & 10.95 & 0.12 & accept \\
\hline 8 & Use of technology & 0 & 0 & 0 & 0 & 7 & 4 & 4 & 9.39 & 11.78 & 14.17 & 11.78 & 0.09 & accept \\
\hline 9 & $\begin{array}{c}\text { Psychological } \\
\text { development }\end{array}$ & 0 & 0 & 1 & 8 & 2 & 4 & 0 & 6.71 & 9.12 & 11.53 & 9.12 & 0.26 & accept \\
\hline 10 & Special skills training & 0 & 0 & 0 & 1 & 8 & 3 & 3 & 8.38 & 10.77 & 13.17 & 10.78 & 0.19 & accept \\
\hline 11 & $\begin{array}{l}\text { Clarity in providing } \\
\text { information }\end{array}$ & 0 & 0 & 0 & 1 & 2 & 8 & 4 & 9.84 & 12.24 & 14.65 & 12.24 & 0.00 & accept \\
\hline 12 & Resilience training & 0 & 0 & 0 & 0 & 3 & 6 & 6 & 9.95 & 12.36 & 14.77 & 12.36 & 0.40 & Next \\
\hline 13 & $\begin{array}{l}\text { Goal-based } \\
\text { management }\end{array}$ & 0 & 0 & 0 & 0 & 5 & 9 & 0 & 9.04 & 11.40 & 13.78 & 11.41 & 0.00 & accept \\
\hline 14 & $\begin{array}{l}\text { Development of critical } \\
\text { thinking }\end{array}$ & 0 & 0 & 1 & 1 & 5 & 5 & 3 & 8.65 & 11.11 & 13.54 & 11.10 & 0.13 & accept \\
\hline 15 & Formal learning & 0 & 0 & 0 & 1 & 8 & 3 & 3 & 8.65 & 11.06 & 13.46 & 11.06 & 0.06 & accept \\
\hline 16 & $\begin{array}{l}\text { Knowledge } \\
\text { management }\end{array}$ & 0 & 0 & 0 & 1 & 9 & 2 & 3 & 8.46 & 10.84 & 13.23 & 10.84 & 0.13 & accept \\
\hline 17 & $\begin{array}{l}\text { Training in the form of } \\
\text { various assumptions }\end{array}$ & 0 & 0 & 0 & 0 & 6 & 6 & 3 & 9.56 & 11.94 & 14.34 & 11.95 & 0.14 & accept \\
\hline 18 & $\begin{array}{l}\text { Culture of action and } \\
\text { practice }\end{array}$ & 0 & 0 & 0 & 1 & 3 & 8 & 3 & 9.32 & 11.72 & 14.13 & 11.72 & 0.21 & accept \\
\hline 19 & $\begin{array}{l}\text { Team building in the } \\
\text { form of a specific } \\
\text { structure }\end{array}$ & 0 & 0 & 0 & 0 & 10 & 2 & 3 & 8.79 & 11.16 & 13.55 & 11.17 & 0.00 & accept \\
\hline 20 & Preserving dignity & 0 & 0 & 0 & 0 & 6 & 6 & 3 & 9.43 & 11.18 & 14.20 & 11.81 & 0.00 & accept \\
\hline 21 & $\begin{array}{l}\text { Forming thought- } \\
\text { provoking teams }\end{array}$ & 0 & 0 & 0 & 0 & 2 & 8 & 5 & 9.98 & 12.39 & 14.79 & 12.79 & 0.45 & Next \\
\hline 22 & Discipline management & 0 & 0 & 0 & 0 & 9 & 4 & 2 & 8.94 & 11.32 & 13.71 & 11.42 & 0.53 & Next \\
\hline 23 & Motivational rewards & 0 & 0 & 0 & 0 & 6 & 8 & 1 & 8.94 & 11.33 & 13.72 & 11.34 & 0.20 & accept \\
\hline 24 & Teamwork & 0 & 0 & 0 & 1 & 8 & 5 & 1 & 8.61 & 10.99 & 13.38 & 11.00 & 0.13 & accept \\
\hline 25 & Job rotation & 0 & 0 & 0 & 0 & 2 & 8 & 5 & 10.40 & 12.78 & 15.18 & 12.79 & 0.00 & Next \\
\hline 26 & Job security & 0 & 0 & 0 & 1 & 1 & 8 & 5 & 8.70 & 11.18 & 13.64 & 11.17 & 0.87 & Next \\
\hline 27 & Motivating & 0 & 0 & 0 & 4 & 5 & 2 & 4 & 7.44 & 9.03 & 11.43 & 9.14 & 0.1 & accept \\
\hline 28 & $\begin{array}{l}\text { Information systems } \\
\text { planning }\end{array}$ & 0 & 0 & 0 & 3 & 2 & 5 & 5 & 8.76 & 10.77 & 12.50 & 9.39 & 0.35 & Next \\
\hline 29 & $\begin{array}{l}\text { Direct communication } \\
\text { with managers }\end{array}$ & 0 & 0 & 0 & 3 & 3 & 6 & 3 & 7.28 & 9.35 & 11.55 & 11.58 & 0.04 & accept \\
\hline 30 & Loyalty making & 0 & 0 & 0 & 1 & 1 & 7 & 6 & 6.76 & 8.33 & 11.43 & 10.18 & 0.1 & accept \\
\hline
\end{tabular}


Table 3. Results of the third survey step and the mean of experts' opinions

\begin{tabular}{|c|c|c|c|c|c|c|c|c|c|c|c|c|c|c|}
\hline \multirow{3}{*}{ 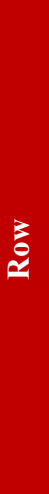 } & 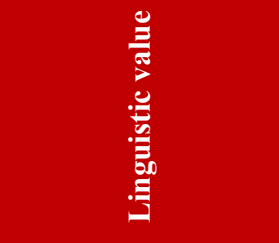 & $\frac{\overrightarrow{0}}{3}$ & 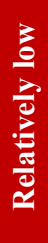 & $\stackrel{3}{9}$ & 䍘 & 焉 & 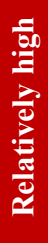 & $\begin{array}{l}\frac{\pi}{00} \\
\frac{0}{\Xi} \\
\frac{0}{0}\end{array}$ & \multirow{3}{*}{$\stackrel{\Xi}{\overparen{E}}$} & \multirow{3}{*}{$\stackrel{乛}{\Xi}$} & \multirow{3}{*}{ 亶 } & \multirow{3}{*}{ 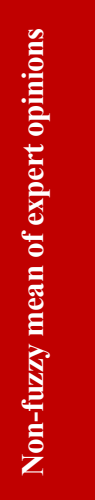 } & \multirow{3}{*}{ 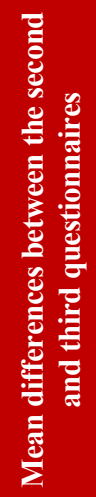 } & \multirow{3}{*}{ 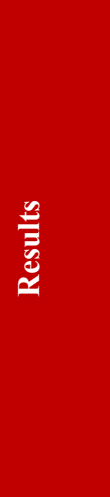 } \\
\hline & Numerical value & 1 & 2 & 3 & 4 & 5 & 6 & 7 & & & & & & \\
\hline & $\begin{array}{l}\text { Sub-criteria - fuzzy } \\
\text { value }\end{array}$ & $\stackrel{\tilde{m}}{\stackrel{f}{\epsilon}}$ & $\begin{array}{l}\tilde{n} \\
\stackrel{\oplus}{=}\end{array}$ & $\begin{array}{l}\hat{F} \\
\text { ம் }\end{array}$ & $\begin{array}{l}\hat{n} \\
\hat{n}\end{array}$ & $\begin{array}{l}\hat{E} \\
\hat{\theta}\end{array}$ & $\begin{array}{l}\hat{m} \\
\hat{=} \\
\hat{\theta}\end{array}$ & $\begin{array}{l}\frac{\pi}{2} \\
\cong \\
\Xi\end{array}$ & & & & & & \\
\hline 1 & Analyst staff & 0 & 0 & 0 & 0 & 3 & 11 & 1 & 9.19 & 11.59 & 13.99 & 11.92 & 0.13 & Accept \\
\hline 2 & Resilience training & 0 & 0 & 0 & 0 & 3 & 6 & 6 & 9.95 & 12.36 & 14.77 & 12.45 & 0.0 & Accept \\
\hline 3 & $\begin{array}{l}\text { Forming thought- } \\
\text { provoking teams }\end{array}$ & 0 & 0 & 0 & 1 & 1 & 8 & 5 & 8.70 & 11.18 & 13.64 & 11.25 & 0.05 & Accept \\
\hline 4 & $\begin{array}{l}\text { Discipline } \\
\text { management }\end{array}$ & 0 & 0 & 0 & 0 & 3 & 11 & 1 & 8.49 & 10.59 & 12.9 & 12.12 & 0.37 & Reject \\
\hline 5 & Job rotation & 0 & 0 & 0 & 0 & 3 & 00 & 1 & 9.49 & 10.40 & 12.10 & 13.02 & 0.32 & Reject \\
\hline 6 & Job security & 0 & 0 & 0 & 0 & 3 & 11 & 1 & 8.11 & 11.19 & 12.11 & 13.91 & 0.11 & Accept \\
\hline 7 & $\begin{array}{l}\text { Information systems } \\
\text { planning }\end{array}$ & 0 & 0 & 0 & 0 & 3 & 00 & 1 & 7.29 & 11.00 & 11.90 & 12.42 & 0.39 & Reject \\
\hline
\end{tabular}

third steps was revealed to be less than the threshold of 0.2; therefore, the survey was stopped at this step. The removed variables were related to discipline management, job rotation, information systems planning with a threshold higher than 0.2 . As a result, 3 out of 30 components were removed from the final conceptual model of the research by performing the survey at three steps, rendering for the final model with 27 components. The crisis management model with the approach of the HR management system is presented in Table 4.

Table 4. Crisis management model with a human resources management system approach

\begin{tabular}{|c|c|c|c|}
\hline \multirow[b]{2}{*}{ Crisis } & \multicolumn{3}{|c|}{ Human resource management } \\
\hline & $\begin{array}{l}\text { Human } \\
\text { resource } \\
\text { recruitment }\end{array}$ & Human resource improvement & Human resource maintenance \\
\hline $\begin{array}{l}\text { Performance } \\
\text { speed (time } \\
\text { pressure) }\end{array}$ & $\begin{array}{l}\text { Creative and } \\
\text { innovative } \\
\text { staff }\end{array}$ & $\begin{array}{c}\text { Informal learning } \\
\text { Coaching and mentoring } \\
\text { Continuous training to maintain morale and } \\
\text { composure in times of crisis } \\
\text { Utilization of modern equipment and technologies }\end{array}$ & $\begin{array}{c}\text { Culture of action and practice } \\
\text { Team making in the form of a } \\
\text { specific structure } \\
\text { Preservation of dignity }\end{array}$ \\
\hline $\begin{array}{l}\text { Uncertainty } \\
\text { (threat level) }\end{array}$ & $\begin{array}{l}\text { Multi-skilled } \\
\text { staff }\end{array}$ & $\begin{array}{l}\text { Psychological development } \\
\text { Special skills training } \\
\text { Clarity in providing information }\end{array}$ & $\begin{array}{c}\text { Forming thought-provoking teams } \\
\text { Discipline management } \\
\text { Motivational rewards } \\
\text { Teamwork }\end{array}$ \\
\hline $\begin{array}{l}\text { Organizational } \\
\text { disorder } \\
\text { (degree of } \\
\text { control) }\end{array}$ & Flexible staff & $\begin{array}{c}\text { Resilience training } \\
\text { Goal-based management } \\
\text { Development of critical thinking }\end{array}$ & $\begin{array}{l}\text { Job rotation } \\
\text { Job security } \\
\text { Motivating }\end{array}$ \\
\hline $\begin{array}{l}\text { Number of } \\
\text { reaction } \\
\text { options }\end{array}$ & Analyst staff & $\begin{array}{c}\text { Formal learning } \\
\text { Knowledge management } \\
\text { Training in the form of various assumptions }\end{array}$ & $\begin{array}{l}\text { Information systems planning } \\
\text { Direct communication with } \\
\text { managers } \\
\text { Creating loyalty }\end{array}$ \\
\hline
\end{tabular}




\section{Discussion and Conclusion}

The results of a study conducted by Askari et al. showed that the quality of crisis management operations was better in the headquarters where the HR management system was established. Since cultural factors, such as teamwork spirit, overcoming fear, specialism, self-sacrifice, rumor avoidance, tendency to new technologies, and dominant and pioneer culture in the HR management process had a great impact on the crisis management process, highlighting the need for effective HR management (9).

Shojaei et al. reported that there was a significant relationship between the allocation of HRs and the implementation level of critical success factors in project-based organizations (10). The findings of research carried out by Ahmadi et al. indicated that HR played a vital role in the stages of crisis prevention, shock, deterioration, chronicity, containment, and learning. Cultural factors, such as teamwork spirit, overcoming fear, specialism, self-sacrifice, rumor avoidance, tendency to new technologies, and dominant and pioneer culture in the HR management process had a great impact on the crisis management process (11).

The components of planning, developing, and applying HRs have significant influences on the crisis management process due to the moderating role of culture. The selection and recruitment activities, team building in the form of a specific structure, HR information system planning, and performance appraisal, as well as the staff training system in the field of crisis management, motivation, and discipline management, have a significant impact on the crisis management process (1).

Such factors as management (technical, general, operational, and planning), motivational, organizational environment, maintenance (health, safety, financial, facilities, or welfare), educational and research, structural, and spiritual affect the management of the hospital HRs in the crisis management of earthquake (12). Awareness of human resources about the potential crises of the organization and providing knowledge and developing skills in them to ensure their proper performance in crisis is highly important in HR planning. In addition, an adequate reward system can also improve employees' performance in crisis (13).
Sustainable development, identity and power, product development, and organizational quality and adaptability, as well as low job quit rate of key employees, are among the necessary capacities requiring to be deal with to prevent organizational crisis (14). Moreover, a strong focus on creativity is effective in crisis management $(15,16)$. Human resources can be most efficient by the proper organization of manpower and job rotation (17). The role of knowledge and human capital in crisis time is significant, and education is the most important factor in empowering $\mathrm{HRs}$ in the face of organizational crisis $(18,19)$. Sufficient information, specialism, and experience, as well as using employee participation can lead to effective decision making and help managers in crisis management (20).

In order to demonstrate the fastest performance in crisis management, most attention should be paid to the recruitment of HRs. This means that according to the conceptual model, the emphasis on employing creative and innovative employees maximizes the performance speed in times of crisis. To this end, the organization is recommended to reconsider its recruitment policies in a way that leads to the introduction of new ideas and creative currents into the organization.

To have the least amount of uncertainty in crisis management, most attention should be paid to improving HRs. In other words, based on the conceptual model, psychological development, special skills training, and clarity in information delivery minimize uncertainty in times of crisis. Therefore, to succeed in this field, the organization is suggested to reconsider its policies in such a way that prioritizes the development and training of HRs.

The provision of information clearly and through official and legal channels are among the most important measures that would prevent the spread of rumors and reduce tensions and concerns in times of crisis incidence. The psychological development of HRs is also an effective measure that increases the mental and psychological capacity of employees to deal with threats and ambiguities caused by environmental uncertainty. Optimism and avoidance of negative and stressful attitudes would be very effective in increasing an individual's productivity in crisis management. The purpose of training special 
skills should be to increase the workforce's flexibility and their ability to consider various aspects; therefore, it would be possible to plan multiple goals and replace programs.

The least amount of organizational disorder in crisis management would be observed provided that the most attention is paid to the maintenance of HRs. In other words, according to the conceptual model, emphasis on job security, job rotation, and motivation minimize the amount of organizational disorder in times of crisis. Therefore, in order to succeed in this field, the organization must reconsider its policies in such a way that the HRs working in the organization feel safe and valuable. Moreover, a job security guarantee is one of the most significant factors that make employees more attached to the organization and prioritize the benefits of the organization over personal interests in any case. As a result, the organizational disorders would be reduced in any situation (e.g., in times of crisis). Furthermore, employees experience different organizational conditions and tasks by job rotation, through which they would be prepared to perform various tasks and more coordination would be provided between employees and different positions in the organization, which in turn is very effective in reducing disorders.

Finally, it should be noted that motivation is also the driving force that, with the help of sacrifice and redoubled efforts of employees, allows the organization to get through the most difficult conditions. The second and the last priorities in this area were related to recruitment and improvement, respectively. The greatest attention should be paid to recruiting HRs in the optimal HR management system to have the largest number of response options in crisis management. This means that, according to the conceptual model, the emphasis on employing analyst staff would maximize the number of response options in times of crisis incidence. Therefore, in order to succeed in this field, the organization must reconsider its recruitment policies in a way that leads to the entry of capable employees with the ability to solve problems in the organization.

The ability to suggest and review different solutions in problem-solving and make the best decision are largely an inherent characteristic of individuals. The recruitment of capable people in this field would increase the options for dealing with the crisis and improve the efficiency of the decisions and actions. The second and last priorities in this area were respectively related to maintenance and improvement.

\section{Acknowledgments}

The authors would like to express their gratitude to all participants who contributed to perform this research project.

\section{Conflict of Interests}

The authors declare that there is no conflict of interest.

\section{References}

1. Ahmadi FS, Nakhoda M, Esmaeli GM, Babalhavaeji F. Presenting a crisis management model in Iran's archival centers: pre-crisis and confronting stage. Iran J Inform Manag 2017; 3(1): 163-80. [In Persian].

2. Nojoumi A. Proposing a strategic model for technological crisis management - a case study on south pars gas complex - Assaluyeh-Bushehr-Iran. J Appl Res Geographical Sci 2019; 20(56): 205-21. [In Persian].

3. Kalayi HS, Kalayi HSM. Presenting a comprehensive pattern of crisis leadership for Basij leaders and managers. Quart Basij Strategic Res 2015; 18(68): 31. [In Persian].

4. Grant RM. Contemporary strategy analysis: text and cases. $9^{\text {th }}$ ed. New Jersey: John Wiley \& Sons; 2016

5. Mann S. Human resources and emergency planning: preparing local governments for times of crisis. Public Administ Quart 2014; 38(2): 163-205.

6. Manole C, Alpopi C, Colesca SE. The strategic role of human resources development in the management of organizational crisis. Econ Ser Manag 2011; 14(1): 207-21.

7. The five-year plan of the Iranian Red Crescent Society (2017-2022). Ratified at the 98th Session of the Supreme Council of the IRCS, Tehran, Iran; 2017.

8. Ritchie BW. Chaos, crises and disasters: a strategic approach to crisis management in the tourism industry. Tourism Manag 2004; 25(6): 669-83.

9. Askari Masouleh S, Afshar M, Mohammadi M. The effect of human resources management system on the quality of crisis management operations (case study: headquarters of Tehran municipality crisis management). J Emerg Manag 2016; 5(1): 39-47. [In Persian].

10. Shojaei M, Vedadi DA. Critical success factors in project-based organizations (Case study: companies in the field of ICT). Crisis Manag J 2016; 7(27): 83. 
[In Persian].

11. Ahmadi SA, Rasuli R, Rajabzadeh Ghatari A, Pouya Gholizadeh P. Presenting a crisis management model with emphasis on human resources management system for hospitals of Tehran. J Public Administ 2012; 4(10): 1-24. [In Persian].

12. Karimi $H$. Identifying the effective factors in human resources management in earthquake in Imam Sajad Hospital. Quart Sci J Rescue Relief 2010; 2(1): 71-84.

13. Athamneh S. HR Planning for crisis management. Human resource planning for the 21 st century 2018 Sep 12. London: Intech Open; 2018.

14. Holtskog H, Ringen G. Opportunities in the wake of crisis. Proc CIRP 2013; 7: 73-8.

15. Koroglu BA, Eceral TO. Human capital and innovation capacity of firms in defense and aviation industry in Ankara. Proc Soc Behav Sci 2015; 195: 1583-92.

16. Salam MA, Khan SA. Lessons from the humanitarian disaster logistics management. Benchmarking Int $\mathrm{J}$ 2020; 27(4): 1455-73.

17. Stahl GK, Brewster CJ, Collings DG, Hajro A. Enhancing the role of human resource management in corporate sustainability and social responsibility: a multi-stakeholder, multidimensional approach to HRM. Hum Resource Manag Rev 2020; 30(3): 100708.

18. Khorram-Manesh A. Flexible surge capacity-public health, public education, and disaster management. Health Promot 2020; 10(3): 2.

19. Veenema TG, Lavin RP, Griffin A, Gable AR, Couig MP, Dobalian A. Call to action: the case for advancing disaster nursing education in the United States. J Nurs Scholarship 2017; 49(6): 688-96.

20. Meechang K, Leelawat N, Tang J, Kodaka A, Chintanapakdee C. The acceptance of using information technology for disaster risk management: a systematic review. Eng J 2020; 24(4): 111-32. 